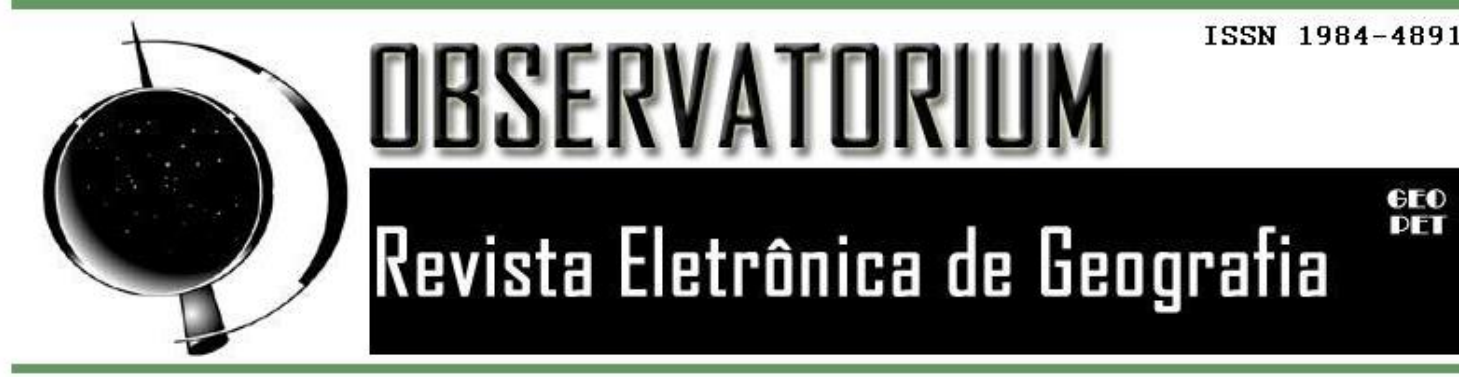

\title{
Teoria anticolonial e currículo escolar brasileiro
}

\author{
Anticolonial theory and brazilian school curriculum
}

\section{José Roberto Nunes de Azevedo}

Doutor em Geografia pela Unesp e Professor da Rede Pública de Ensino do

Estado de São Paulo.

E-mail: joseazevedo@prof.educacao.sp.gov.br

\section{Resumo:}

A reflexão acerca da escola pública à luz das políticas públicas empreendidas pela União, estados e municípios é um ponto necessário para apreendermos as formas pela qual são conduzidas a formação dos alunos na educação básica. Para alcançar o objetivo lançamos mãos de metodologia qualitativa baseada na leitura de documentos institucionais voltados à seara educacional e revisão bibliográfica em torno do assunto proposto e, por outro lado, da experiência e participação no âmbito escolar na última década no Estado de São Paulo e Mato Grosso do Sul. As primeiras pistas da investigação em andamento nos levam a perceber que há um longo caminho a ser percorrido no que tange ao alcance de melhores condições de aprendizagem e superação do fracasso escolar tanto no Estado de São Paulo como no Brasil, muito embora haja um quadro bastante desigual quando considera-se os resultados da educação escolar pública.

Palavras-Chave: Educação; Escola Pública; Teoria Anticolonial; Currículo; Políticas educacionais.

\begin{abstract}
:
Reflecting on public school in the light of public policies undertaken by the Union, states and municipalities is a necessary point for us to understand the ways in which students' education in basic education is conducted. In order to achieve this goal, we used a qualitative methodology based on the reading of institutional documents related to the educational field and bibliographic review around the proposed subject and, on the other hand, the experience and participation in the school environment in the last decade in the State of São Paulo and Mato. Grosso do Sul. The first clues of the ongoing investigation lead us to realize that there is a long way to go in terms of achieving better learning conditions and overcoming
\end{abstract}




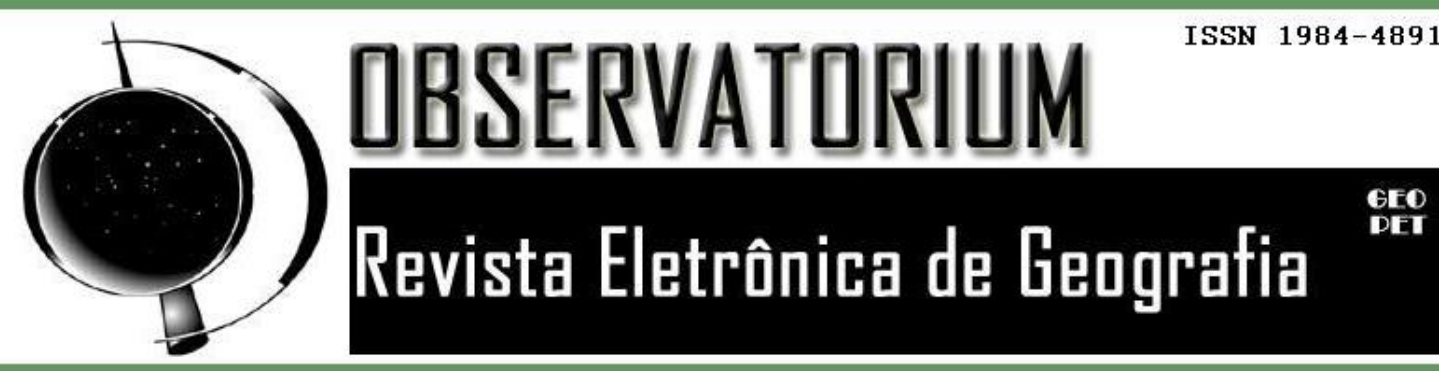

school failure in both São Paulo and Brazil, although there is a rather unequal picture when considering the results of public school education.

Keywords: Education; Public school; Anticolonial theory; Curriculum; Educational policies.

\section{Introdução:}

O problema educacional se coloca como chave da solução do problema humano tanto no aspecto individual como da sociedade, pois a "ciência é também política, e o cientista deve saber porque é utilizada, como é utilizada e em favor dos interesses de quem ela é utilizada" (ANDRADE, 2008, p.13).

A educação básica de qualidade é um direito assegurado pela Constituição Federal e demais aparatos legislacionais sendo a formação escolar a base para o desenvolvimento humano. Desta forma, conceber a educação escolar como ponto chave de nossa discussão faz-se importante e possibilita adentrarmos no cerne da questão.

Não obstante desde 1988, com a Constituição da República em seu artigo 208 temos as seguintes disposições:

O dever do Estado com a educação será efetivado mediante a garantia de: educação básica obrigatória e gratuita dos 4 (quatro) aos 17 (dezessete) anos de idade, assegurada inclusive sua oferta gratuita para todos os que a ela não tiveram acesso na idade própria; (Redação dada pela Emenda Constitucional $n^{0} 59$, de 2009) (Vide Emenda Constitucional $n^{0} 59$, de 2009)

Nidelcoff (1983) questiona em seu livro o papel da escola no âmbito da estrutura social tendo em vista que esta entidade que recebeu por muito tempo a tarefa de garantir ao conjunto das pessoas condições igualitárias em um ambiente menos desigual não tem atingido seus reais objetivos sendo necessários, portanto, repensar as funções a que são atribuídas.

A escola como representante principal da ação educacional no Brasil vem recebendo ataques significativos de uma política educacional que não privilegia a democracia e a formação cidadã, plural e crítica. Como bem destacou 


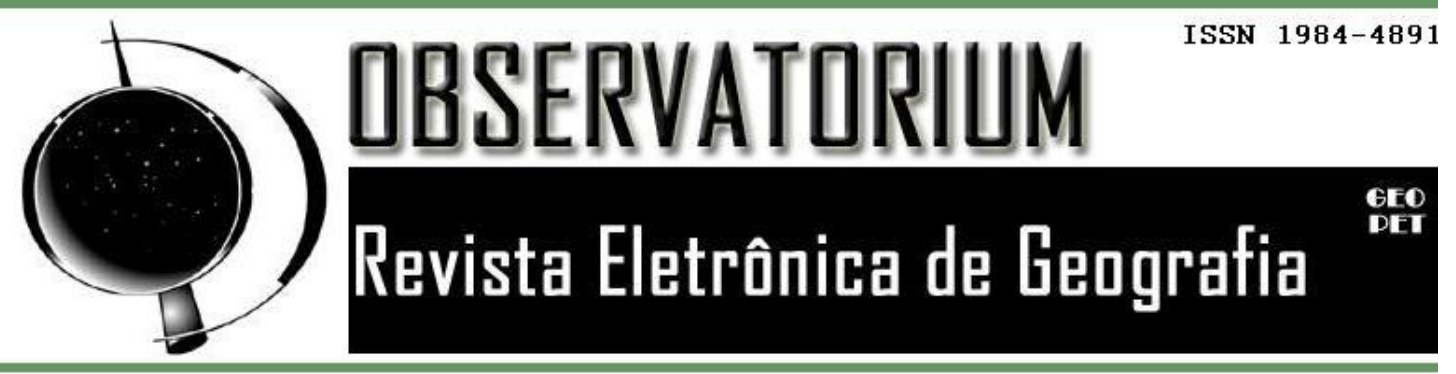

Xavier, Ribeiro e Noronha (1994, p.238), “a política educacional não tem uma trajetória autônoma em relação ao desenvolvimento histórico da formação social brasileira”. Tão logo, segundo as autoras em questão a mesma "encaminha no sentido de legitimar a exclusão de amplos setores sociais das oportunidades de acesso à educação" (idem).

Freire e Guimarães (1982) colocam que a prática docente e a prática dentro da escola devem ser consideradas e analisadas à luz da reflexão, não obstante, há uma série de questões que se instalam no âmbito escolar que independem do indivíduo. Por isso, temos que observar a escola como um ambiente de aprendizagem que está ancorada na contradição, pois está impregnada de posturas e formas de representação daqueles que a constroem, mas segue um direcionamento maior que vem definido pelo próprio Estado.

Apesar dessa estrutura hierárquica que caracteriza o espaço escolar a formação dos educandos não está enrijecida e nem deve ser construída por relações de poder, muito embora, o currículo possa funcionar como uma maneira de controle das capacidades de transformação social e política desenvolvida pelo cidadão. Portanto, como diria Freire e Guimarães (1982, p. 51), necessita-se atentarmos para "Importância fundamental do desenvolvimento da capacidade crítica dos educandos enquanto sujeitos de conhecimento, desafiados pelo objeto a ser desvelado".

Cabe nos questionar quais são os objetivos de cada formação e neste aspecto qual a contribuição do currículo para a população brasileira.

Temos observado através de nossos estudos que se tem atribuído uma importância maior no âmbito das políticas educacionais aos resultados a serem alcançados e atenção restrita ao processo de desenvolvimento de pessoas dotadas de consciência e entendimento do seu papel no mundo. Desta forma, camufla-se o verdadeiro significado do projeto de sociedade que deseja-se construir em nome dos interesses econômicos e políticos vigentes.

Não obstante, como diria Demo (2010) não basta termos consciência e sim tomarmos posições. Afinal não se tem mudanças e/ou transformações se apenas agirmos de forma a reproduzir uma constatação, ou seja, o caminho se faz na medida em que cada profissional compreende seu papel no contexto de ação, 


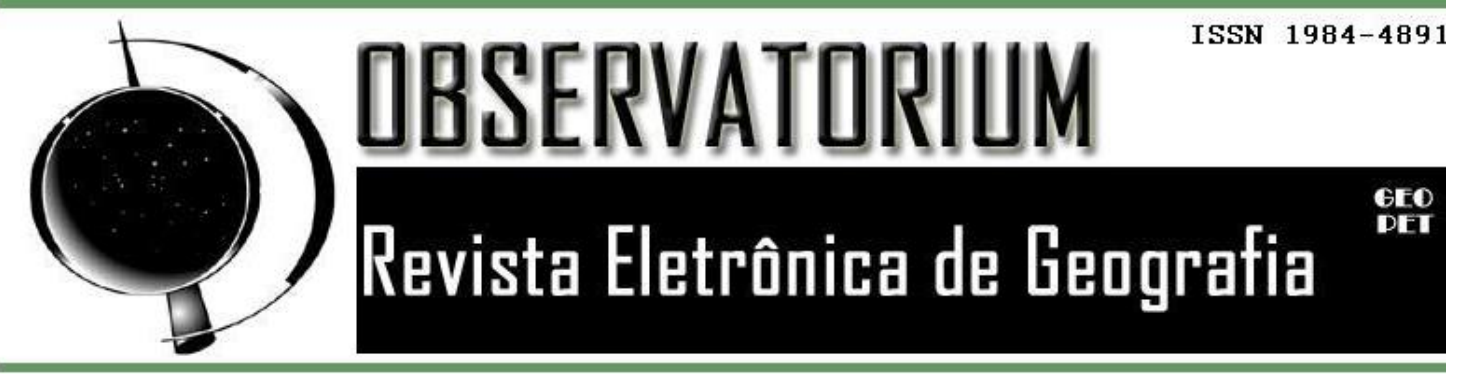

O desenvolvimento humano deve estar encimado nos pressupostos educacionais e neste aspecto através da formação crítica podemos garantir o exercício da cidadania bem como o acesso pelos estudantes ao conjunto de direitos sociais, civis, político-econômicos e culturais.

Não podemos apenas fitar as mudanças sem considerar as relações mais sutis e disfarçadas presentes na aplicação da política educacional no país e especialmente no Estado de São Paulo, bem como, suas consequências e significados para a sociedade.

\section{Teoria anticolonial, educação e currículo}

A Teoria anticolonial busca trazer a dimensão expropriatória e alienante que marcou o processo de formação de corpos e de mentes no Brasil e demais países colonizados graças à sanha capitalista voltada ao acúmulo de capitais.

Para os limites do presente texto devemos compreender que a Teoria anticolonial não se desvincula dos processos educativos às relações econômicas e políticas, mas, ao contrário, dá-lhe o traço perfeito de uma relação que se constrói. Portanto, é na base do processo educativo adotado pelos estados e legitimado pelo Estado democrático de direito que se configura a sociedade que aí está.

A Teoria anticolonial, desta forma envolve o conjunto de processos que se aplicam a realidade social e que em nosso projeto possibilita traçar uma configuração mais ampla das características dos países subdesenvolvidos, particularmente do Brasil. Assim, através de mecanismos de controle e condução da política educacional a máquina governamental neoliberal consegue criar às condições necessárias para manter os níveis de aprendizagem aquém do esperado e perpetuar a pobreza, somada a restrita democracia em uma sociedade em que a cidadania caminha a passos lentos.

A educação brasileira não configura-se como um todo homogêneo pois envolve um conjunto de cenários e contextos próprios a cada região brasileira e 


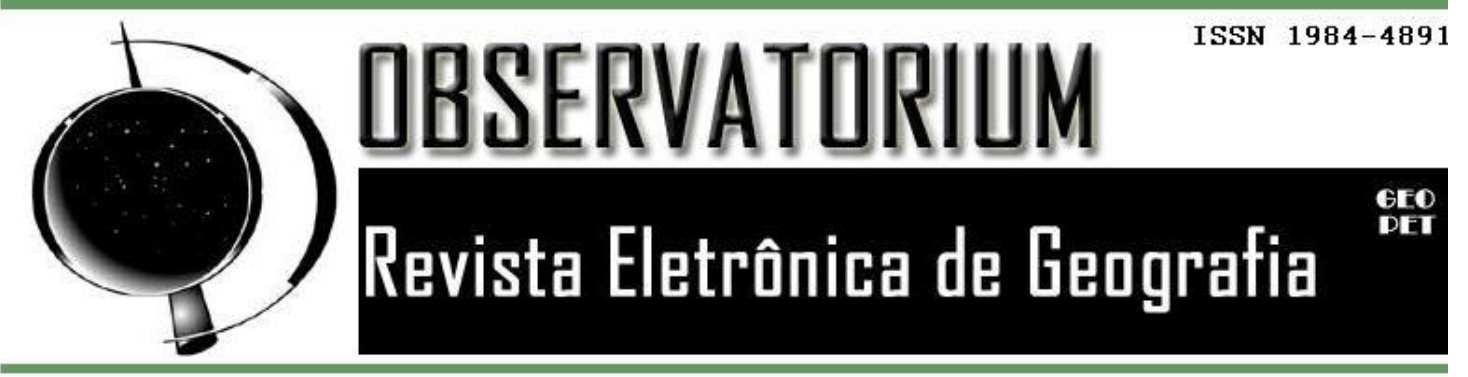

O currículo escolar está vinculado à concepções de mundo daqueles que o estruturam e deste modo não é neutro daí ser preciso analisar os elementos que o caracterizam para tomarmos posse das suas consequências em termos de formação e construção social.

O currículo escolar demonstra o ser humano que queremos formar e, portanto, pode moldar o cidadão que estamos formando através de uma mera indicação para o mercado de trabalho ou para uma compreensão do mundo mais vasta e geral, vinculada as demandas da vida.

Apesar da existência de um consenso internacional a respeito da importância da educação há muito a se construir e avançar. Felizmente, a partir da Conferência Mundial da Educação para Todos ocorrida em 1990 na Tailândia tivemos a condução no Brasil da nova Lei de Diretrizes e Bases (1996) e do Plano de Metas denominado "Compromisso Todos pela Educação" cujo foi instituído pelo Decreto Federal nº 6.094 de 2007. Não obstante, isto não foi suficiente para garantir a melhoria da qualidade da educação básica e há na atualidade um quadro desanimador no tocante aos avanços sociais.

\section{Política educacional, fracasso escolar}

A política educacional paulista está ancorada nos princípios manutenção das benesses da classe dominante na medida em que não privilegia os alunos advindos das classes subalternas e valoriza a manutenção do status quo.

Nessa trajetória consideramos diferentes recortes e escalas espaciais, sendo que neste momento direcionamos o foco da análise para o Estado de São Paulo, tendo em vista a magnitude das estratégias do capital e do processo de precarização das relações de trabalho do professorado e os impactos sociais mais gerais e em particular para os trabalhadores que estão em sala de aula.

Em termos de valorização dos professores é fato que as políticas de cunho neoliberal estão prejudicando drasticamente as condições a que estão submetidos e impactam diretamente, em aspectos particulares como direitos trabalhistas, fragmentação da categoria profissional, salários desestimuladores, plano de carreiras, etc. 


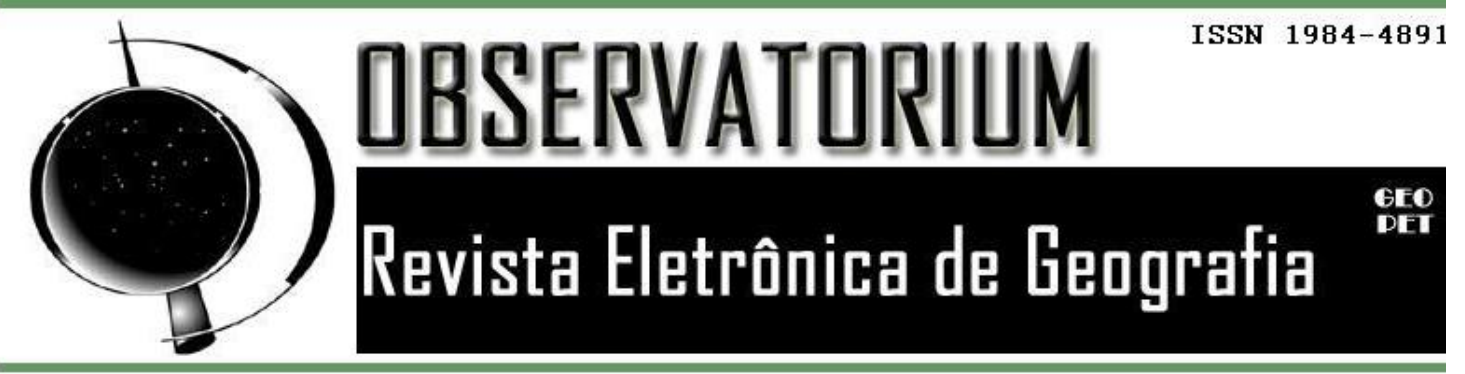

Diante desses argumentos e pistas assinaladas reiteramos por fim como prática necessária a filtragem e consequente ruptura em relação aos discursos oficiais imbuídos com os ideários burgueses e que na ansiedade de descaracterizar insistem em marginalizar as lutas, as vontades e ideário da classe trabalhadora da qual é parte integrante os professores.

Por fim, devemos lembrar que para ocorrer a possibilidade de termos em todo país professores bem preparados e com formação geral e específica avançada é fundamental repensar as políticas educacionais bem como o processo de trabalho a que estão submetidos atualmente está categoria profissional, haja vista que se não houver valorização e mérito em relação ao trabalho desenvolvido pelos mesmos ocorre a desmotivação, desarticulação e desinteresse em relação ao universo educacional.

O "mapa" das transformações políticas orquestram as mudanças no currículo paulista e desencadeiam a cada alteração de governo e/ou secretário em exercício novas configurações as quais atestam e legitimam a agenda política caracterizada pelos mandos e desmandos de uma política arbitrária da Secretária Estadual de Educação Paulista e Brasileira que tem valorizado os cortes públicos e perdas irreparáveis quanto a qualidade da educação básica e superior.

A título de exemplo devemos lembrar que desde o Plano Nacional de Educação, Lei 10.172/2001 são aspectos norteadores: a valorização dos profissionais da educação, bem como, a ampliação do atendimento aos educandos em outros níveis e graus de ensino, permitindo acesso irrestrito ao conjunto da população à educação de qualidade, sejam pelas instituições públicas ou privadas. Não obstante qual o alcance dessa assertiva?

As nossas investigações tem nos indicado que no período de vigência do Plano Nacional de Educação (PNE), desde o seu início até 2008, constatasse que, embora em ritmo distinto, menos de um terço das unidades federadas (26 Estados e o Distrito Federal) apresentaram resposta positiva, uma vez que, dentre eles, apenas 8 formularam e aprovaram os seus Planos de Educação.

Também a questão da qualidade nos incomoda e faz repensar o seu significado, pois como coloca Demo (2010, p.10) "Na qualidade não vale o maior, 


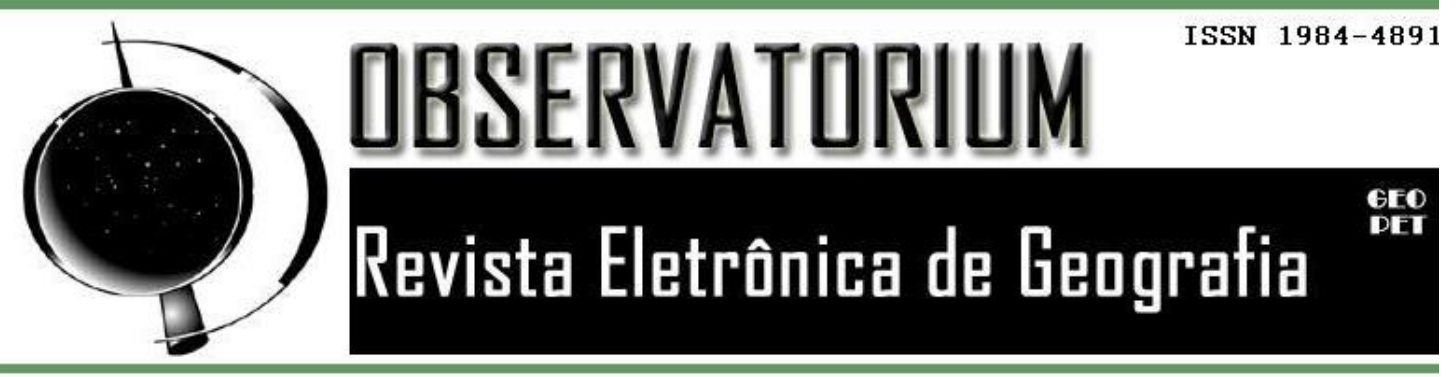

mas o melhor; não o extenso, mas o intenso" e neste aspecto a educação pública precisa não apenas crescer numericamente como avançar em torno da formação para cidadania e participação social de todos.

Percebemos ao longo das últimas décadas que a cada mudança de governo altera-se também a estrutura curricular e as metas e objetivos vinculados às expectativas de formação dos estudantes. Neste sentido, não há uma continuidade e sim inúmeras fragmentações no processo educacional paulista marcadamente política.

A política educacional paulista vincula-se aos padrões historicamente herdados caracterizados pelo hiato entre formação para o trabalho e alienação para a vida. Conforme nos esclarece Romanelli (1980) historicamente observouse no Brasil uma incapacidade de as camadas dominantes reorganizarem o sistema educacional de forma que se atendesse harmonicamente tanto a demanda social de educação quanto às novas necessidades de formação de recursos humanos exigidos pela economia em transformação.

Dessa forma, o aparelho escolar revela o funcionamento ideológico latente que por trás do aparente recrutamento democrático e da formalização das regras, realiza de fato uma seleção social segundo os critérios da classe dominante que ao mesmo tempo em que cria as condições para aplicação de uma agenda neoliberal possibilita a precarização das relações de trabalho. Assim, é como Enguita (1989, p.3250 coloca: “O êxito escolar requer um alto grau de adesão aos fins, aos meios e aos valores da instituição que nem todos os estudantes apresentam. Embora não faltem os que aceitam incondicionalmente o projeto de vida que lhe oferece a instituição."

Por trás do ensino há muitas questões a serem discutidas. Observamos, por exemplo, que tem se atribuído a culpa pelas condições atuais da escola pública e também a qualidade deficitária do ensino aos alunos ora aos professores e quando não à ausência da família na escola. Não obstante a aprendizagem de um estudante envolve aspectos educacionais complexos, não apenas o professor. A família, a comunidade escolar e o Estado devem estar presentes para garantir uma base educacional sólida. 


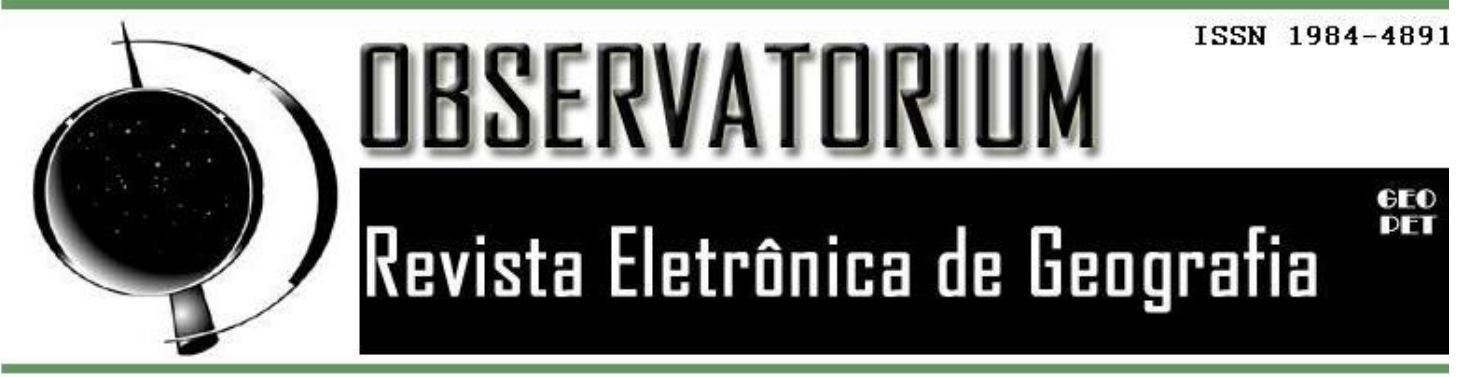

Nos últimos anos, especialmente, a partir de 2010 temos observado há inúmeras mudanças na agenda educacional brasileira tendo em vista adequar as normas e características locais as demandas internacionais e suas respectivas avaliações e conceitos de produtividade e qualidade. Nota-se que a educação passa a ser medida e ou pretensiosamente avaliada como algo mensurável e que precisa ser direcionada para atender simplesmente às demandas do mercado e por assim dizer a formação de mão de obra barata, qualificada, preparada para atender as atuais necessidades do país. Podemos nos perguntar a essa altura: qual projeto de nação que queremos?

Novos e velhos elementos entram em cena, como aspectos voltados à educação técnica tão familiar e controversa em décadas do século XX. É como a Geografia da educação brasileira estivesse em pleno rearranjo para um novo projeto de Brasil que visa enquadrá-lo no âmbito das mudanças estruturais do mundo globalizado. Teríamos uma escola que resiste as pressões?

Faz-se no Brasil um retrocesso sem precedentes quanto ao desmonte da educação pública, a qual é atingida em todos os aspectos pela ação conservadora da ala governante. E se por um lado, avançou-se durante algumas décadas nos números de escolas criadas e no acesso das crianças e adolescentes aos bancos escolares, por outro, não ocorreu a mesma preocupação com a melhora e manutenção da qualidade do ensino. Por outro lado, se na agenda nacional, sobretudo na última década do século XX e primeira década do século XXI tivemos o acesso mais amplo das classes sociais menos abastadas a Educação superior, parece-nos que estamos à beira de um abismo.

O fracasso escolar é claramente evidenciado pela enorme quantidade de crianças e adolescentes que anualmente deixam de frequentar os bancos escolares (evasão) e passam a compor o exército industrial de reserva, somado, pois, aos elevados índices de reprovação existentes nas escolas. Segundo Barreto (2010, p. 438): "A construção do fracasso do aluno pela escola, a ênfase dada ao seu "tratamento", bem como as estratégias empregadas para resolver o problema, terminam por exacerbar o fracasso e responsabilizar o aluno pelo insucesso". Nesse sentido, para autora, "do ponto de vista individual, a experiência da 


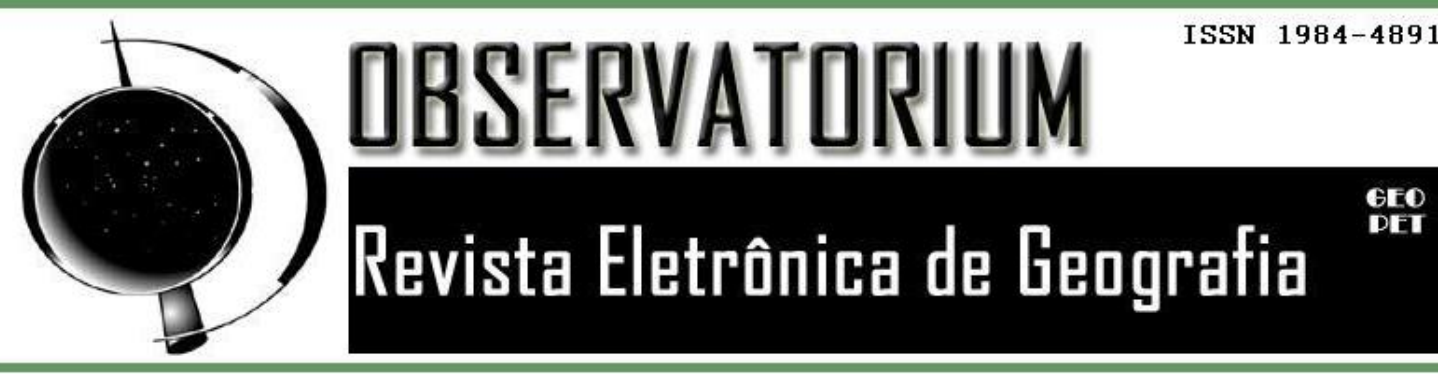

incapacidade de acompanhar o processo escolar se volta contra o aluno, pondo em xeque seu valor como pessoa" (BARRETO, 2010, p.438)

Problemas preocupantes e antigos como repetência e evasão escolar aparentemente resolvido e/ou minimizados no século XX na maior parte dos países ocidentais pobres retornam e parecem não mais preocupar os administradores educacionais das principais pastas governamentais.

A função técnica da transmissão dos conhecimentos é utilizada para garantir aos herdeiros da ordem social os acessos aos benefícios do poder, conferidos pelo sucesso escolar. A seleção social desempenhada dissimuladamente pela escola é efetiva e tornada aceitável aos excluídos por um processo de produção ideológica que culmina, ao fim da escolaridade, com a premiação do diploma, o qual é concedido aos indivíduos e representa os valores da classe dominante.

Essa função só pode ser eficazmente desempenhada pela ênfase numa falsa anatomia do sistema de ensino frente às relações de classes. Portanto, a dita escolarização parece firmar-se como uma tendência do capitalismo que, aliás, não está ao alcance de todos, haja vista que se ancora nos referenciais propostos na produtividade.

A escola privilegia a classe dominante na medida em que legitima as políticas educacionais vigentes, sendo estes critérios geralmente baseados na desigualdade social.

Quando se coloca, por exemplo, a questão do fracasso escolar devemos compreender que é preciso lidar com a gestão de um projeto pedagógico que assegure a esta clientela condições dignas de aprendizagem que não se isolem apenas no conteúdo pelo conteúdo, mas sim que o signifique para suas vidas dando-lhe sentido e significado para que motivados se interessem por participar do processo escolar.

Assim, pode-se concluir que o aproveitamento dos alunos não é fruto apenas do efeito do trabalho docente, mas resultado de uma conjunção de fatores, dos quais se destacam o modo de gestão da escola e a participação dos pais e ou responsáveis. 


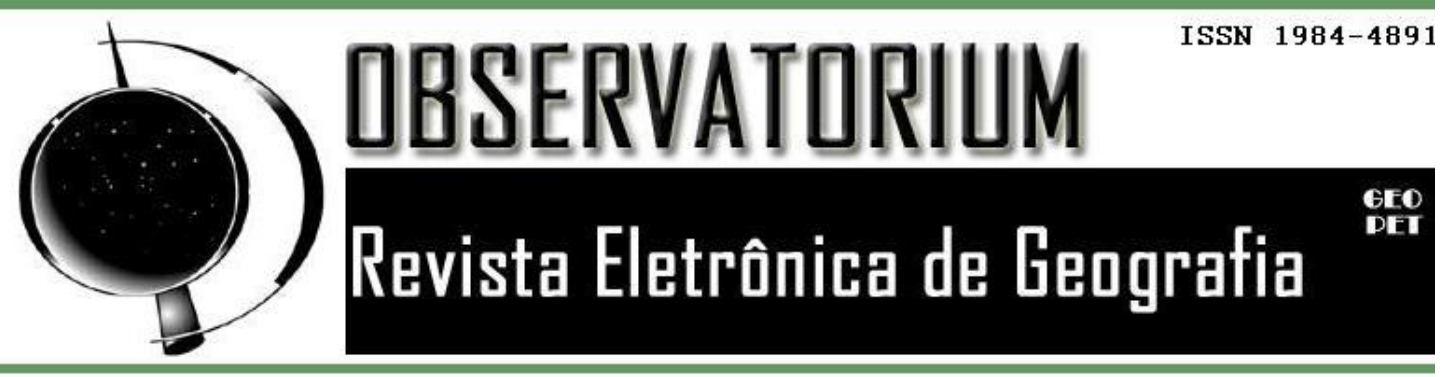

pessoas a pensar por conta própria, aprendendo a enfrentar novos desafios, criando novas respostas em vez de somente repetir velhas formulas”.

Do mesmo modo cabe a escola reaprender a trabalhar com esta realidade dos alunos marcados pelo estigma da exclusão do fracasso e do preconceito nos bancos escolares e entender que tais alunos, crianças e adolescentes, não estão à mercê de um conjunto de fatores políticos e econômicos que legitimam sua inserção e permanência na escola.

Por outro lado, é necessário que o professor tenha clareza de suas convicções políticas e pedagógicas em relação ao trabalho escolar: o que pensa sobre o papel da escola na formação de cidadãos ativos e participantes na vida social, sobre a relação entre o domínio de conhecimentos e habilidades e as lutas sociais pela melhora das condições de vida e pela ampla democratização da sociedade; como fazer para derivar dos objetivos amplos aqueles que correspondem às tarefas de transformação social, no âmbito do trabalho pedagógico concreto nas escolas.

Portanto é preciso que a escola entenda seu papel social e sua função numa sociedade de grupos muito diversificados. É o momento de se rever estudando e adequando a população a quem deve servir as normas e práticas prejudiciais, os critérios de promoção absurdos, maus currículos, exigências arbitrarias de avaliações, professores despreparados, guias e orientações inadequadas, medidas administrativas impensadas etc., para que assim, de fato inicie-se um quadro de transformações profundas que culmine numa estrutura societal democrática e contra ideológica.

\section{Considerações Finais}

O estudo acerca da Teoria anticolonial e currículo escolar brasileiro é uma forma de descortinar as características da educação e a partir delas refletir acerca da atual situação da formação escolar no Brasil e particularmente no Estado de São Paulo.

A Teoria anticolonial revela-se como ponto de partida dessa investigação na medida em que somos produtos de um processo de espoliação 


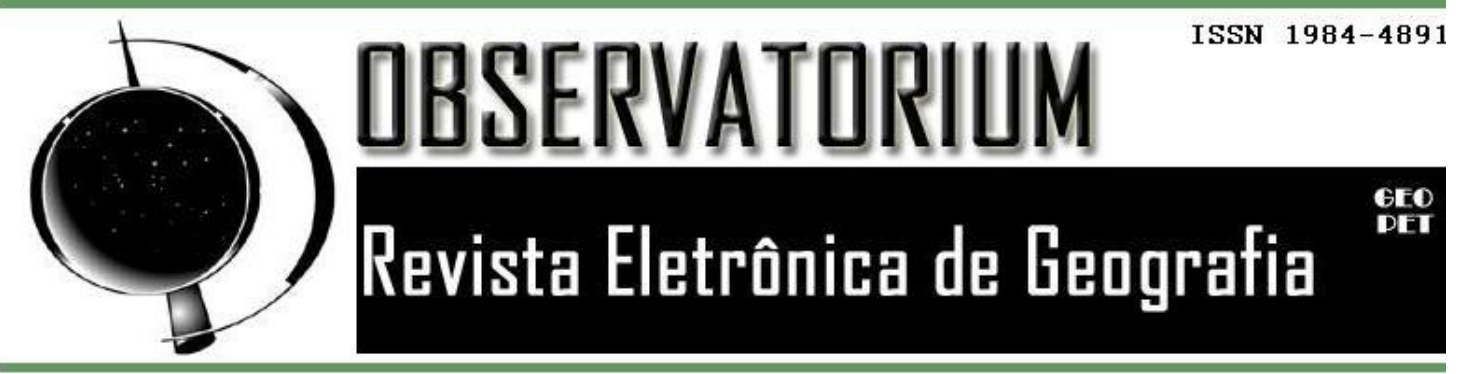

que marcou profundamente nossa história. Entendemos que não é possível compreender o presente e quanto menos o futuro se não observarmos as transformações políticas e econômicas que direcionaram e determinaram a política educacional.

Relacionar temas tão caros à sociedade como currículo e fracasso escolar passam pela reflexão da forma como têm sido conduzido a formação do professor e o papel da escola no âmbito da sociedade de classes. Neste aspecto, o desafio é entender quais serão os rumos da educação escolar para o século XXI de tal forma que não caminhemos para a barbárie e o retrocesso. Como bem retratou Sampaio (2000, p.67) a "alternativa da elite é que tem conduzido o país a barbárie" e neste se aspecto passamos por um modelo de inserção subordinada mais geral cujo reflete-se no desemprego, na cultura consumista propagada, na concentração de renda e austeridade fiscal. Tão logo, precisamos caminhar rumo a retomada da construção nacional e dos valores da civilização.

As políticas públicas educacionais vistas a partir da dimensão geográfica possibilitarão uma análise qualitativa dos processos educativos e deverá nos guiar na análise das características e contradições em torno do tema.

Acreditamos que a formação para a vida passa pela construção de sujeitos conscientes de seu papel no mundo no qual se rompa com a mentalidade colonizada, eivada de inferioridade e preconceitos.

A perspectiva neoliberal presente na atual configuração do capitalismo do século XXI regem os contornos da política educacional adotadas no Brasil mas não sabemos os principais processos que definem as relações de poder empreendidas e por isso não podemos prescindir da investigação contínua.

Se o Estado tem buscado as alternativas para superação dos problemas educacionais ou se suas políticas educacionais estão simplesmente preocupadas em manter o status quo é sem dúvida um elemento preocupante nesta pesquisa.

A participação popular na definição das direções da política educacional devem ser apreendidas e os princípios democráticos valorizados sob pena de retroceder frente aos interesses de mercado. 


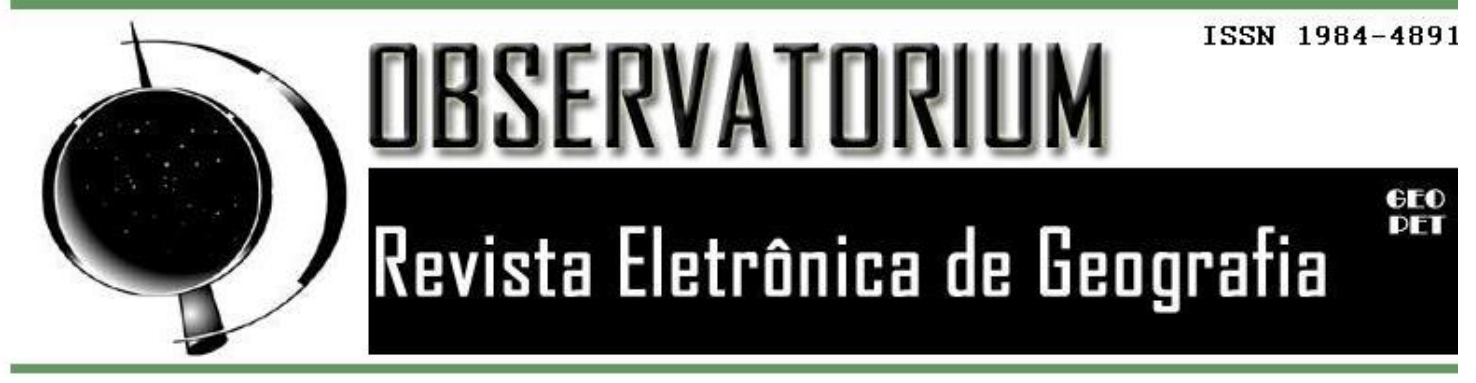

BRASIL. Ministério da Educação. Base Nacional Comum Curricular. Proposta preliminar. Segunda versão revista. Brasília: MEC, 2016. Disponível em: < http://basenacionalcomum.mec.gov.br/images/BNCC_publicacao.pdf>. Acesso em: 26/11/2017

BRASIL. Ministério da Educação. Secretaria de Educação Básica. Secretaria de Educação Continuada, Alfabetização, Diversidade e Inclusão. Conselho Nacional da Educação. Diretrizes Curriculares Nacionais Gerais da Educação Básica/ Ministério da Educação. Secretária de Educação Básica. Diretoria de Currículos e Educação Integral. - Brasília: MEC, SEB, DICEI, 2013.

BRASIL. Secretaria de Educação Fundamental. Parâmetros Curriculares Nacionais: apresentação dos temas transversais, ética / Secretaria de Educação Fundamental. - Brasília: MEC/SEF, 1997.

BUENO, D. da C. F.; AZEVEDO, J. R. N. entre a teoria e a prática: os professores nas escolas públicas paulistas e seus desafios no século XXI. Fórum Ambiental da Alta Paulista,v.11, n.4, p.370-383, 2015.

CANIVEZ, P. Educar o cidadão? ensaios e textos. Campinas: Papirus, 1991.

CARVALHO, C. do P. F. de. A educação cidadã na visão empresarial: 0 telecurso 2000. Campinas: Autores Associados, 1999.

CAVALCANTI, L. de S. Geografia, escola e construção do conhecimento. Campinas: Papirus, 1998.

CIAVATTA, M. República dos professores - perdemos o status, não a dignidade. Universidade e sociedade, São Paulo, ano XI, nº 26, ANDES, 2002.

DELORS, J. Educação: um tesouro a descobrir. São Paulo. Cortez, Brasília: MEC/Unesco, 1998.

DEMO, P. Avaliação qualitativa. Campinas: Autores Associados, 2010.

ENGUITA, M. F. A face oculta da escola. Porto Alegre: Artes Médicas, 1989.

FREIRE, P. Conscientização. São Paulo: Moraes, 1980.

FREIRE, P. Educação como prática da liberdade. Rio de Janeiro: Paz e Terra, 1992.

FREIRE, Freire. Pedagogia da autonomia. São Paulo: Paz e Terra, 2005. 


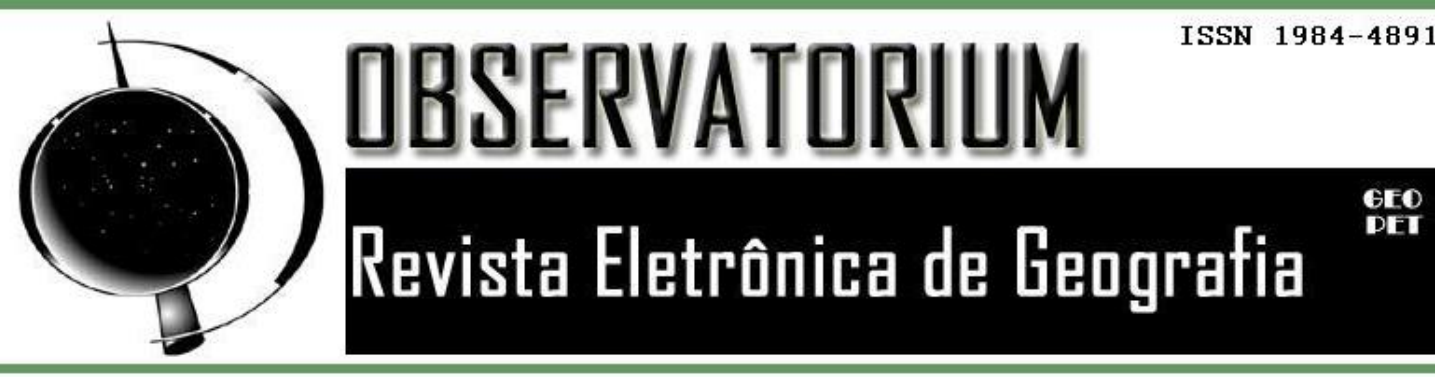

RODRIGUES, N. Da mistificação da escola à escola necessária. São Paulo: Cortez, 1988.

SAMPAIO, M. M.F.; MARIN, A. J. Precarização do trabalho docente e seus efeitos sobre as práticas curriculares. Educ. Soc. Campinas, vol. 25, n.89, 2004. p.12031225 .

SAMPAIO, P. A. Dilema e desafios postos para a sociedade brasileira. Estudos Avançados. São Paulo, v.14 (40), 2000. p. 64-76.

São Paulo (Estado) Secretaria da Educação. A nova estrutura administrativa da Secretaria da Educação do Estado de São Paulo: por uma gestão de resultado com foco no desempenho do aluno. São Paulo: SE, 2013. 212 p.

SÃO PAULO (Estado) Secretaria da Educação. Matrizes de referência para a avaliação Saresp: documento básico/Secretaria da Educação; coordenação geral, Maria Inês Fini. - São Paulo: SEE, 2008, 2009, 2010, 2011, 2012, 2013, 2014, 2015 .

SEVERINO, A. J. Filosofia da educação. São Paulo: FTD, 1995.

TOMMASI, L. de; WARDE, M. J.; HADDAD, S. (Orgs.). O Banco Mundial e as políticas educacionais. São Paulo: Cortez, 1996.

VESENTINI, J. W. Educação e ensino de Geografia: instrumentos de dominação e/ou de libertação. In: CARLOS, A. F. A. (Org). A Geografia na sala de aula. São Paulo: Contexto, 2008.

VLACH, V. Geografia e ensino: a necessidade de um contra discurso. Educação e Filosofia. Uberlândia, v.1, n.2, 1987.

XAVIER, M. E. S. P.; RIBEIRO, M. L. S.; NORONHA, O. M. História da educação: a escola no Brasil. São Paulo: FTD, 1994. 